\title{
Effects of sprouting and salt stress on polyphenol composition and antiradical activity of einkorn, emmer and durum wheat
}

\author{
Fabio Stagnari, ${ }^{1}$ Angelica Galieni, ${ }^{1,2}$ Sara D'Egidio, ${ }^{1}$ Beatrice Falcinelli, ${ }^{3}$ Giancarlo Pagnani, ${ }^{1}$ \\ Roberta Pace, ${ }^{4}$ Michele Pisante, ${ }^{1}$ Paolo Benincasa ${ }^{3}$ \\ ${ }^{1}$ Faculty of Bioscience and Technologies for Food, Agriculture and Environment, University of Teramo, \\ Teramo; ${ }^{2}$ Research Centre for Vegetable and Ornamental Crops, Council for Agricultural Research and \\ Economics, Monsampolo del Tronto (AP); ${ }^{3}$ Department of Agricultural, Food and Environmental Sciences, \\ University of Perugia, Perugia; ${ }^{4}$ CGS Seeds, Acquasparta (TR), Italy
}

\begin{abstract}
Germination is related with improvements of nutritional value of seeds, since it promotes accumulation of health-promoting phytochemicals. However, only few studies have investigated on phytochemicals accumulation during sprouting under sub-optimal conditions. Thus, we investigated the effect of salinity during germination of an einkorn (TMoM), an emmer (TDiZ) and a durum wheat (TDuC) genotype on the total polyphenols (TPC), free- and bound-phenolic acids [PAs; i.e. caffeic acid, syringic acid, Pcoumaric acid, trans-ferulic acid, and salicylic acid] contents and antiradical activity (Trolox equivalent antioxidant capacity; TEAC) of sprouts and wheatgrass. The following $\mathrm{NaCl}$ treatments were applied: 0 (control), 25, 50 and $100 \mathrm{mM} \mathrm{NaCl}$ concentration throughout the whole experiment, or 50 and $100 \mathrm{mM} \mathrm{NaCl}$ until sprout stage and then $0 \mathrm{mM}$ until wheatgrass stage (recovery treatments). TMoM showed higher total bound-PAs both in sprouts and wheatgrass with respect to the other Triticum genotypes $(+25 \%$ and $24 \%$, respectively) as well as of total bound-PAs and bound-SA in the recovery treatments. Moderate salt stress signifi-
\end{abstract}

Correspondence: Fabio Stagnari, Faculty of Bioscience and Technologies for Food, Agriculture and Environment, University of Teramo, via R. Balzarini 1, 64100 Teramo (TE), Italy.

E-mail: fstagnari@unite.it

Key words: Salt stress; Phenolic acids; Triticum monococcum L. ssp. monococcum; Triticum turgidum L. ssp. dicoccum; Triticum turgidum L. ssp. durum.

Acknowledgments: we gratefully acknowledge Dr. Massimo Fiorani of Prometeo S.r.l. for providing the hulled wheat genotypes and Mr. Silvano Locchi for technical assistance in the laboratory experiment.

Received for publication: 10 October 2016.

Revision received: 14 February 2017.

Accepted for publication: 15 February 2017.

CCopyright F. Stagnari et al., 2017

Licensee PAGEPress, Italy

Italian Journal of Agronomy 2017; 12:848

doi:10.4081/ija.2017.848

This article is distributed under the terms of the Creative Commons Attribution Noncommercial License (by-nc 4.0) which permits any noncommercial use, distribution, and reproduction in any medium, provided the original author(s) and source are credited. cantly increased all the investigated variables in TDiZ. Salt stress induced higher TPC and TEAC as well as total free-PAs values till $50 \mathrm{mM} \mathrm{NaCl}$ in $\mathrm{TDuC}$, whilst significantly lowered total boundPAs due to the negative variation of both P-CA (-84\%) and transFA $(-81 \%)$ acids. Results indicate that salinity during germination could be efficiently modulated to improve the nutritional quality of sprouts, wheatgrass and cereal-based products.

\section{Introduction}

Sprouting is reported to be associated with improvements of nutritional value of seeds, since it promotes accumulation of health-promoting phytochemicals (phenolic acids, flavonoids, and vitamins) (Oh and Rajashekar, 2009).

Cereal sprouts (i.e. caryopses within 3-4 days after germination) and microgreens (i.e. young seedlings of 1-2 weeks age, known as wheatgrass) may represent a valid alternative in human feeding (Benincasa et al., 2015). They allow avoiding processing treatments (i.e. milling and baking) thus maintaining the nutritional value of grains, mainly represented by substantial quantities of bioactive compounds - including phenolic acids - which are unevenly distributed in kernels, with aleurone layer having the highest antioxidant activity, followed by the bran fraction. The hulled wheat species, i.e. the diploid wheat einkorn (Triticum monococcum ssp. monococcum, genome AA) and the tetraploid emmer (Triticum turgidum ssp. dicoccum, genomes AABB), are less bred species and may be used for sprouting, to better satisfying target requirements of consumers compared to the most cultivated soft and durum wheat.

Recent works have focused on phenolic acids and flavonoids contents in ancient and modern wheat genotypes (Shewry and Hey, 2015), both on grains (Dinelli et al., 2011) and germinated sprouts (Benincasa et al., 2015; Hung et al., 2011). However, only few studies have investigated on the response in terms of phytochemicals accumulation during sprouting under sub-optimal conditions.

The content and composition of bioactive compounds in sprouts and wheatgrass depend on many factors such as genotype, growth stage and environmental conditions during sprouting (Cevallos-Casals and Cisneros-Zevallos, 2010). It is well acknowledged that plants under various abiotic stresses (i.e. drought, salinity, high light and chilling; Lim et al. 2012; Oh and Rajashekar, 2009) accumulate several phytochemicals, which play a major role in the adaptation of plants to unfavourable growing conditions (Guo et al., 2014; Yuan et al., 2010). Quality traits, as well as the level and activity of bioactive compounds occurring in 
foods of plant origin may be modified using a range of biotechnological and agronomic practices. However, to date little is known about the effect of abiotic stress on phytochemical accumulation in edible sprouts and the application of environmental stress to enhance their quality traits as well as the actual translatability of the enriched-bioactive compounds to biological benefits in lifestyle-related diseases. The effect of salt stress on bioactive compounds accumulation was studied in sprouts of radish (Yuan et al., 2010), broccoli (Guo et al., 2014), lentil (Świeca, 2015), peanut (Kavas et al., 2015), alfalfa (Wang et al., 2009) and buckwheat (Lim et al., 2012). In wheat (Triticum aestivum L.) the impact of salt stress was only evaluated in terms of germination rates and biometric determinations (Datta et al., 2009) while no quality trait was assessed.

Our hypothesis is that the content of bioactive compounds of ready-to-eat sprouts and wheatgrass of Triticum genotypes may be enhanced by both germination process and salt stress conditions applied during sprouting. The parameters assessed to characterise these effects were total phenolic content, radical scavenging activity and the content of some phenolic acids (both free- and boundfractions) in grains, sprouts and wheatgrass of three different Triticum genotypes (einkorn, emmer and durum wheat).

\section{Materials and methods}

\section{Plant material and germination conditions}

Grains of einkorn (Triticum monococcum L. ssp. Monococcum var Monlis, TMoM), emmer (Triticum turgidum L. spp. dicoccum (Schrank ex Schübler) Thell. var Zefiro, TDiZ) and durum wheat (Triticum turgidum L. ssp. durum (Desf.) Husnot var Creso, $\mathrm{TDuC}$ ) were collected from different locations of Central Italy and were sown in autumn 2014 in small plots of $3 \mathrm{~m}^{2}$ without replicates at Mosciano S. Angelo (Central Italy, Province of Teramo, $42.75^{\circ} \mathrm{N}, 200 \mathrm{~m}$ a.s.1., Mediterranean climate). The soil was uniform, silty-clay with $1.2 \%$ organic matter. Fertilisation inputs included $60 \mathrm{~kg} \mathrm{ha}^{-1}$ of $\mathrm{N}$; no pest and disease control was performed and weeds were controlled by hand. Grains were hand harvested in July 2015 , at a grain water content lower than $15 \%$ and cleaned from dust and any other contaminants and stored in a dry and cool room until the beginning of the experiment, performed in laboratory.

Germination was carried out to obtain sprouts (growth stage: about $5 \mathrm{~cm}$ shoot length) and wheatgrass (growth stage: about $12 \mathrm{~cm}$ shoot length) of TMoM, TDiZ and TDuC. Caryopses (200 $\mathrm{g}$ for each genotype) were incubated in plastic trays containing filter paper laid over glass balls immersed in 0 (i.e. control), 25, 50 and $100 \mathrm{mM} \mathrm{NaCl}$ solutions $\left(0 \_\mathrm{S}, 25 \_\mathrm{S}, 50 \_\mathrm{S}\right.$ and $100 \_\mathrm{S}$, respectively) throughout the whole experiment, i.e. until either sprout or wheatgrass stage. Additionally two recovery treatments were included consisting of sprouts obtained with 50 and $100 \mathrm{mM} \mathrm{NaCl}$ solutions and then transferred in trays containing distilled water until wheatgrass stage (50_R and 100_R, respectively). Each treatment consisted of 4 trays (replicates) arranged on a completely randomised design; replicates were then regrouped two by two for the chemical analysis.

The trays were placed in a growth chamber at $18^{\circ} \mathrm{C}$ and at light:dark regime of 10:14 hours. Light intensity was set at 200 $\mu \mathrm{mol}$ photons $\mathrm{m}^{-2} \mathrm{~s}^{-1}$, in order to approximate the average light intensity achievable indoor by natural light incoming through a window, with the aim of reproducing the likely environmental con- ditions for homemade production. Distilled water was periodically added to trays to keep the initial $\mathrm{NaCl}$ concentration of each treatment. For $0 \_S$ treatments, sprouts were harvested 5 days after the start of incubation (DAS), while wheatgrass was harvested 8 DAS; for all the other treatments, since salinity slowed germination and seedling growth, sprouts and wheatgrass were sampled when they reached the same growth stages as in the control (Table 1). Recovery-treatments (50_R and 100_R) were sampled only at wheatgrass stage, assuming same analysis values as in $50 \_\mathrm{S}$ and $100 \_$S for sprouts.

For sprouts, the whole plant material was collected, as it is usually in wheat sprouting. By analogy, the whole plant material was taken also for wheatgrass, although only the shoot is normally used to extract juice. Sampled material was stored at $-20^{\circ} \mathrm{C}$ for analytical determinations.

\section{Chemicals}

2,2'-azinobis-(3-ethyl-benzothiazoline-6-sulfonic acid) (ABTS), acetic acid, acetonitrile (HPLC grade), ethyl acetate, were purchased from Carlo Erba (Milan, Italy). Sodium carbonate was provided by Panreac (Barcelona, Spain). Folin-Ciocalteau reagent, hydrochloric acid $(37 \% \mathrm{w} / \mathrm{v})$, methanol, sodium hydroxide, gallic acid (GA), caffeic acid (CA), syringic acid (SRA), P-coumaric acid (P-CA), trans-ferulic acid (trans-FA) and salicylic acid (SA) were purchased from Sigma Aldrich (St. Louis, MO, USA). All standards were prepared as stock solution at $1 \mathrm{mg} \mathrm{mL}^{-1}$ in methanol and stored at $-20^{\circ} \mathrm{C}$ in darkness conditions. Ultra-pure water was obtained from a reverse osmosis system (Technolab, Milan, Italy).

\section{Total polyphenols content}

Total polyphenols content (TPC) determination was performed on grains, sprouts and wheatgrass of TMoM, TDiZ and TDuC, using the Folin-Ciocalteau reagent method (Singleton and Rossi, 1965). Grains (10 g) were milled using a laboratory miller and sieved through a 32-mesh screen. Five grams of milled (grains) or freeze-sampled (sprouts and wheatgrass) material for each replicate were treated with $\mathrm{MeOH}(10 \mathrm{~mL})$ and homogenised with the T-25 Ultra-Turrax (IKA-LAB, Seneco S.r.l., Milano, MI, Italy), then sonicated with Sonis 4 for 1 hour in a cooled water bath. The extracts were centrifuged for 10 minutes at $15,000 \mathrm{~g}$ at $4{ }^{\circ} \mathrm{C}$ and the supernatant was filtered through a Chromafill AO-22/25 polyamide filter. $0.8 \mathrm{~mL}$ of Folin-Ciocalteau reagent were added to aliquots of $0.2 \mathrm{~mL}$ of extracts; after $5 \mathrm{~min}, 0.8 \mathrm{~mL}$ of a $25 \%$ $\mathrm{Na}_{2} \mathrm{CO}_{3}$ solution was added and then deionised water up to $10 \mathrm{~mL}$ final volume. Solutions were maintained at room temperature under dark conditions for $60 \mathrm{~min}$ and the total polyphenols content was determined at $765 \mathrm{~nm}$ using a Perkin Elmer Lambda Bio20 spectrophotometer (Perkin-Elmer, Waltham, MA, USA). Gallic acid (GA) standard solutions were used to calibrate the method; the contents of total polyphenols in each extract was calculated and expressed as mg of GA equivalent (GAE) per $100 \mathrm{~g}$ (dry weight, DW) of sample (mg GAE $100 \mathrm{~g}^{-1} \mathrm{DW}$ ).

\section{Radical scavenging activity}

Radical scavenging activity was measured on TPC extracts, according to the method described by Re et al. (1999). ABTS was dissolved in water to a $7 \mathrm{mM}$ concentration; the ABTS radical was obtained from reaction of ABTS stock solution with $2.45 \mathrm{mM}$ potassium persulphate and allowing the mixture to stand in the dark at room temperature for $12-16 \mathrm{~h}$ before use. The ABTS radical solution was diluted with deionised water to reach an 
absorbance of $0.70 \pm 0.02$ at $734 \mathrm{~nm}$. Thirty $\mu \mathrm{L}$ of differently diluted extracts were added to $2.97 \mathrm{~mL}$ of diluted ABTS radical solution. The absorbance at $734 \mathrm{~nm}$ was evaluated by a Perkin Elmer Lambda Bio 20 spectrophotometer (Perkin-Elmer, Waltham, MA, USA). For each sample, the percentage of inhibition (I\%) after 5 minutes of reaction was plotted as a function of concentration and the Trolox equivalent antioxidant capacity (TEAC) calculated as the ratio of the linear regression coefficient of the sample to that of the Trolox standard (Fluka, Buchs, Switzerland). Results were expressed as $\mu \mathrm{mol}$ of Trolox equivalents (TE) per g (DW) of sample $\left(\mu \mathrm{mol} \mathrm{TE} \mathrm{g}^{-1} \mathrm{DW}\right)$.

\section{Extraction of the phenolic fractions (free and bound)}

The extraction of free phenolic acids (free-PAs) was achieved on grains, sprouts and wheatgrass of TMoM, TDiZ and TDuC, following the procedure of Vaher et al. (2010) with some modifications. One gram of milled (grains) or freeze-sampled (sprouts and wheatgrass) material for each replicate was suspended in $5 \mathrm{~mL}$ of $\mathrm{MeOH} /$ water/acetic acid (70/29.5/0.5 v/v) and homogenised with the T-25 Ultra-Turrax (IKA-LAB, Seneco S.r.l., Milan, Italy) then sonicated with Sonis 4 for 40 minutes at room temperature. After centrifugation at $4,000 \mathrm{~g}$ for $10 \mathrm{~min}$, the supernatant was removed and the extraction was repeated. The combined extracts were evaporated to dryness under a gentle flow of nitrogen and the residues were redissolved in $1 \mathrm{~mL}$ of $\mathrm{MeOH}$. The final extract was filtered through $0.45 \mu \mathrm{m}$ PTFE syringe filters (Phenomenex, Torrance, CA, USA) and stored at $-20^{\circ} \mathrm{C}$ until HPLC analysis.

After extracting free-PAs, the solid residue was hydrolysed according to Kim et al. (2006) with minor modification. Briefly, the residue was digested with $10 \mathrm{~mL} 4 \mathrm{M} \mathrm{NaOH}$; the suspension was sonicated for $40 \mathrm{~min}$ and treated over night at room temperature. After alkaline hydrolysis the supernatant was adjusted to $\mathrm{pH}$ 2 with $6 \mathrm{M} \mathrm{HCl}$. The supernatant was extracted three times with ethyl acetate ( $20 \mathrm{~mL}$ each extraction); the mixture was vigorously vortexed for $1 \mathrm{~min}$ at room temperature, then centrifuged at 4,000 $g$ for $10 \mathrm{~min}$. The three fractions were pooled, evaporated to dryness under a rotary evaporator in vacuum, redissolved in $2 \mathrm{~mL}$ of $\mathrm{MeOH}$ and stored at $-20^{\circ} \mathrm{C}$ until $\mathrm{HPLC}$ analysis.

All the extractions were performed under dim light to avoid sample degradation by photo-oxidation.

\section{Identification and quantification of phenolic com- pounds}

PAs were analysed using an HPLC system consisting of a Perkin Elmer series 200 LC equipped with a UV/VIS detector and controlled through the software TotalChrom Navigator (Version 6.3.1). The separation of the analytes was carried out with a Kinetex C18 column (250x4.6 mm ID, $5 \mu \mathrm{m}$; Phenomenex, Torrance, CA, USA). The mobile phases were water with $1 \%(\mathrm{v} / \mathrm{v})$ acetic acid (A) and 100\% acetonitrile (B) with a solvent flow rate of $1 \mathrm{~mL} \mathrm{~min}-1$ for a total run time of $60 \mathrm{~min}$. The gradient programme was as follows: from $95 \%$ to $84 \%$ solvent A in 20 min, from $84 \%$ to $30 \%$ solvent $\mathrm{A}$ in $20 \mathrm{~min}$, from $30 \%$ to $95 \%$ solvent $\mathrm{A}$ in $10 \mathrm{~min}$ and then $10 \mathrm{~min}$ of post-run for reconditioning. Automatic injections of $20 \mu \mathrm{L}$ of the standards and sample solutions were carried out; UV chromatograms were recorded at 280 $\mathrm{nm}$ (Zhou and Yu, 2004). Identification of PAs was based on their retention times, obtaining suitable chromatographic elution with no interferences or overlapping peaks. Quantitative analysis was based on peak area; the calibration curves, i.e. the peak area versus concentration, were linear in the range of the assessed concentrations $\left(r^{2}>0.992\right)$. The lines of regression, calculated in the range of
5-80 ppm, have been used for quantitative analysis of PAs in the extracts.

\section{Statistical analysis}

To test the effect of Triticum genotypes (TMoM, TDiZ and $\mathrm{TDuC}$ ) on TPC, TEAC, free-PAs and bound-PAs in grains, oneway analysis of variance (ANOVA) was performed.

Data on TPC, TEAC, free-PAs and bound-PAs in sprouts and wheatgrass were subjected to two-way ANOVA, with genotypes (TMoM, TDiZ and TDuC) representing the main factor and sprouting conditions (0_S, 25_S, 50_S, 100_S, 50_R and 100_R) the secondary factor.

All the statistical analyses were performed with R software ( $R$ Development Core Team, 2013). If the ANOVA detected significant differences, means separation was obtained through the Tukey's honestly significant difference (HSD) test. Prior to ANOVA, data were analysed to test the normality and homoschedasticity assumptions.

\section{Results and discussion}

\section{Grains}

The results about total polyphenols content in grains of TMoM, TDiZ and TDuC are reported in Figure 1A. TPC values ranged from 30.8 (TDuC) to $40.3(\mathrm{TMoM}) \mathrm{mg}$ GAE $100 \mathrm{~g}^{-1} \mathrm{DW}$
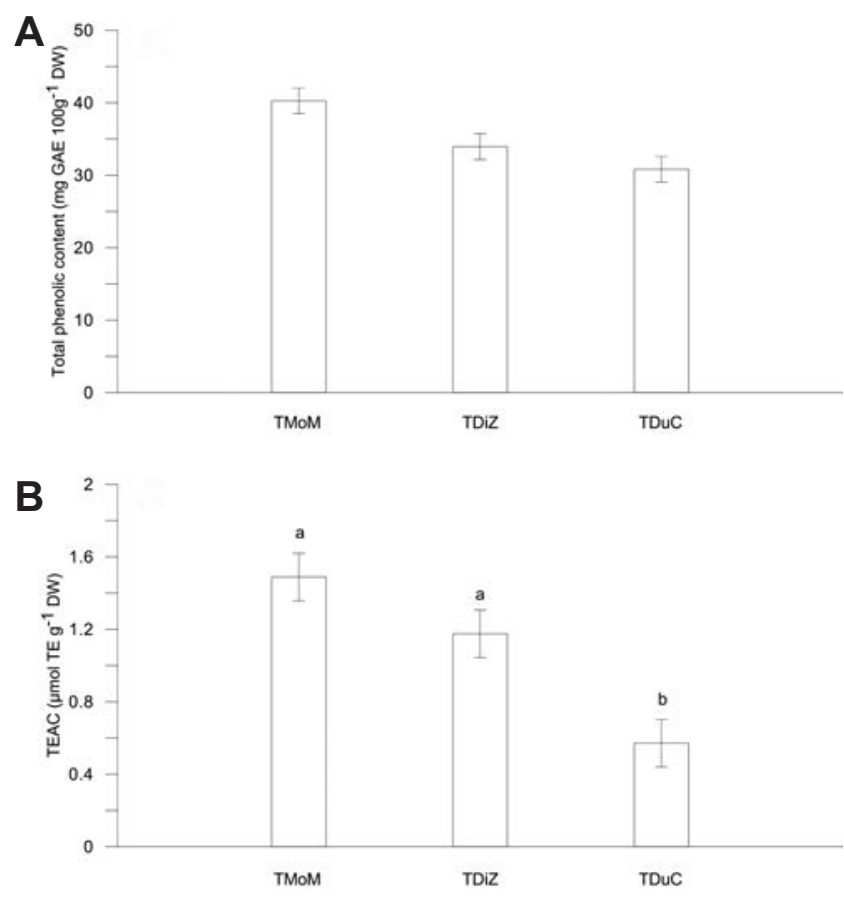

Figure 1. Total phenolic content (mg gallic acid equivalent, GAE, $100 \mathrm{~g}^{-1}$ dry weight, DW) (A) and antiradical activity (TEAC, $\mu$ mol Trolox equivalents, TE, $\left.\mathrm{g}^{-1} \mathrm{DW}\right)(\mathrm{B})$ in grains of $T$. monococcum cv Monlis (TMoM), T. dicoccum cv Zefiro (TDiZ), and T. durum cv Creso (TDuC). Data represent means \pm standard errors, $\mathrm{n}=\mathbf{2}$ independent replicates. Different letters stand for statistically significant differences at $\mathrm{P}<0.05$ (Tukey's honestly significant difference test). 
(Figure 1A); significant differences among genotypes were not detected. These data match with the range reported in literature (Shewry and Hey, 2015; Vaher et al., 2010), while differ from Benincasa et al. (2015), due to higher TPC in TDuC grains. Probably the particular environmental conditions of 2015 (i.e. temperature and rainfall regimes during grain filling) and some abiotic stress factors occurring during kernel development, significantly affected the biosynthesis and accumulation of phenolic compounds (Herbinger et al., 2002).

The effect of genotype was significant in terms of radical scavenging activity, with TMoM and TDuC showing the highest and

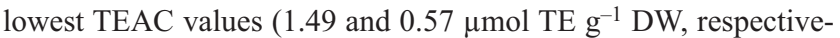
ly; Figure 1B), confirming data by Yilmaz et al. (2015) although with higher and more variable values probably due to the different extraction's assays.

In order to have a better characterisation of wheat genotypes, providing more detailed information when compared with spectrophotometric methods (such as total polyphenols by FolinCiocalteau reagent method), grains extracts were analysed to assess their free and bound phenolic acids fractions. Five phenolic compounds, CA, SRA, P-CA, trans-FA and SA were investigated.

In no-sprouted grains, the bound forms accounted for most of the total phenolic acids content (Table 2) as bound-PAs are crosslinked with the mainly structural components such as hydrolysable tannins, lignins, cellulose and proteins (Gawlik-Dzikiet al., 2012). Averaged over genotypes, trans-FA showed the highest concentration among total bound-PAs in kernels (Table 2), as previously observed (Benincasa et al., 2015).

Regarding the effect of genotype, the content of total free-PAs in grains of TMoM and TDiZ was more than double compared to that of durum wheat, principally due to higher contents of both P$\mathrm{CA}$ and trans-FA (Table 2). An analogous trend was observed for the bound-fraction and the content of total bound-PAs of TMoM and TDiZ which were, on average, over three- fold higher than TDuC (Table 2). Bound trans-FA content lowered by about 52 and $56 \%$ in TDuC with respect to TMoM and TDiZ, while P-CA was on average $97 \%$ lower than the other genotypes, in agreement with Benincasa et al. (2015).

\section{Effect of sprouting and salt stress on polyphenols con- tent and radical scavenging activity}

Figures 2 and 3 report trends of TPC and TEAC as observed respectively in sprouts and wheatgrass of TMoM, TDiZ and TDuC germinated under normal and salt stress conditions.
Averaged over both genotypes and salt treatments, sprouting enhanced TPC from 6-fold (in sprouts) up to over 20-fold (in wheatgrass) and similar increases were also observed for TEAC values (Figure 4A and B), confirming their significant linear correlation $\left(r^{2}=0.98\right)$, as previously observed in some fruits and vegetables (Gorinstein et al., 2007; Kugler et al., 2007). The highest increase was recorded for $\mathrm{TDuC}$, the genotype with the lowest
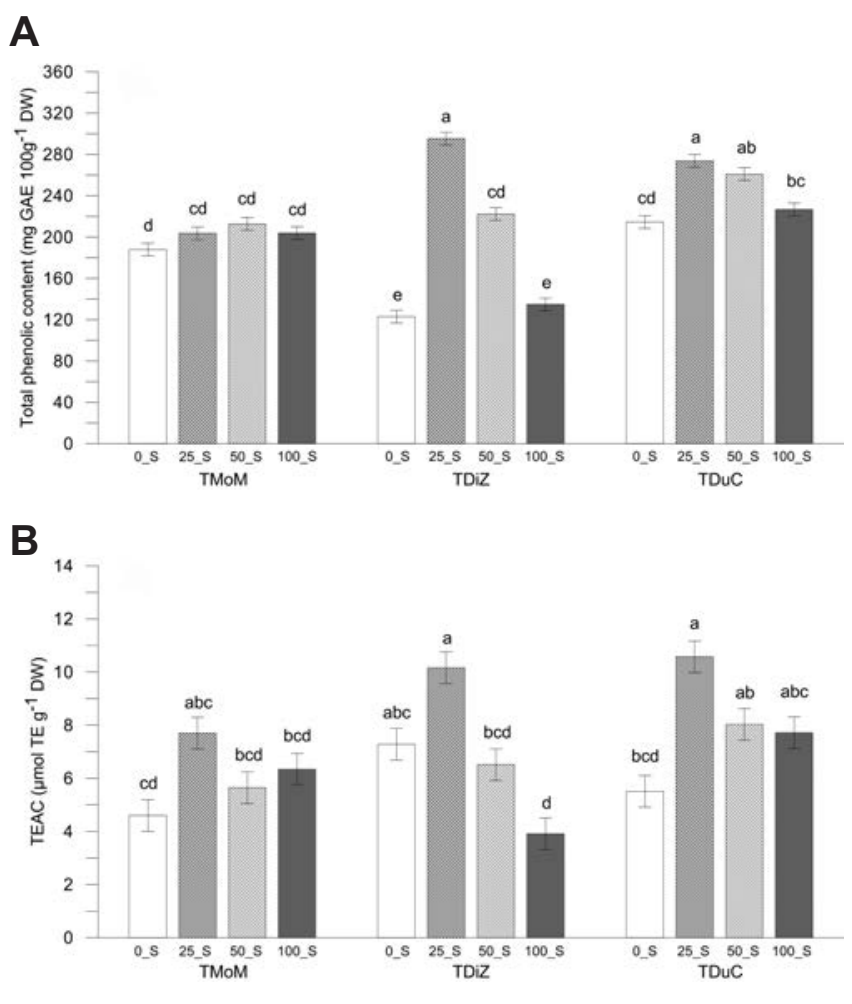

Figure 2. Total phenolic content (mg gallic acid equivalent, GAE, $100 \mathrm{~g}^{-1}$ dry weight, DW) (A) and antiradical activity (TEAC, $\mu$ mol Trolox equivalents, TE $\mathrm{g}^{-1} \mathrm{DW}$ ) (B) in sprouts of T. monococcum cv Monlis (TMoM), T. dicoccum cv Zefiro (TDiZ), and T. durum cv Creso (TDuC), obtained under 0 (i.e. control), 25, 50 and $100 \mathrm{mM} \mathrm{NaCl}$ solutions $\left(0 \_S, 25 \_S, 50 \_S\right.$ and $100 \_S$, respectively). Data represent means \pm standard errors, $n=2$ independent replicates. Different letters stand for statistically significant differences at $\mathrm{P}<0.05$ (Tukey's honestly significant difference test).

Table 1. Sampling details of sprouts and wheatgrass of einkorn (Triticum monococcum L. ssp. monococcum var Monlis), emmer (Triticum turgidum L. spp. dicoccum (Schrank ex Schübler) Thell. var Zefiro) and durum wheat (Triticum turgidum L. ssp. durum (Desf.) Husnot var Creso) during germination.

\begin{tabular}{|c|c|c|c|c|c|c|}
\hline \multirow{2}{*}{ Treatments } & \multicolumn{2}{|c|}{ TMoM } & \multicolumn{2}{|c|}{ TDiZ } & \multicolumn{2}{|c|}{ TDuC } \\
\hline & $\begin{array}{l}\text { Sprouts }^{\circ} \\
\text { DAS }\end{array}$ & $\begin{array}{c}\text { Wheatgrass }{ }^{\#} \\
\text { DAS }\end{array}$ & $\begin{array}{l}\text { Sprouts } \\
\text { DAS }\end{array}$ & $\begin{array}{c}\text { Wheatgrass } \\
\text { DAS }\end{array}$ & $\begin{array}{l}\text { Sprouts } \\
\text { DAS }\end{array}$ & $\begin{array}{c}\text { Wheatgrass } \\
\text { DAS }\end{array}$ \\
\hline 0_S & 5 & 8 & 5 & 8 & 5 & 8 \\
\hline 25_S & 5 & 8 & 5 & 8 & 5 & 8 \\
\hline 50_S & 6 & 9 & 6 & 11 & 6 & 10 \\
\hline 100_S & 7 & 10 & 8 & 13 & 7 & 11 \\
\hline 50_R & - & 9 & - & 9 & - & 9 \\
\hline 100_R & - & 9 & - & 9 & - & 9 \\
\hline
\end{tabular}

TMoM, Triticum monococcum cv Monlis; TDiZ, Triticum dicoccum cv Zefiro; TDuC, Triticum durum cv Creso; DAS, days after the start of incubation. ${ }^{\circ} \mathrm{Growth}$ stage: about $5 \mathrm{~cm}$ shoot length; ${ }^{\sharp}$ growth stage: about $12 \mathrm{~cm}$ shoot length. Grains were subjected to 0 (i.e. control), 25,50 and $100 \mathrm{mM} \mathrm{NaCl}$ solutions (0_S, 25_S, 50_S and 100_S, respectively) throughout the whole experiment, or to 50 and $100 \mathrm{mM}$ NaCl solutions until sprout stage and then to $0 \mathrm{mM}$ until wheatgrass stage (recovery-treatments: $50 \_$R and $100 \_$R, respectively). 
TPC and TEAC values in grains (TPC: up to 7-fold in sprouts, up to 27-fold in wheatgrass; TEAC: up to 13-fold in sprouts, up to 38fold in wheatgrass) (Figure 4A).

The observed increase in total phenolic content and antiradical activity confirmed evidence obtained in cereals (Benincasa et al., 2015; Donkor et al., 2012) as well as in several other species belonging to Leguminosae and Brassicaceae families (Cevallos-

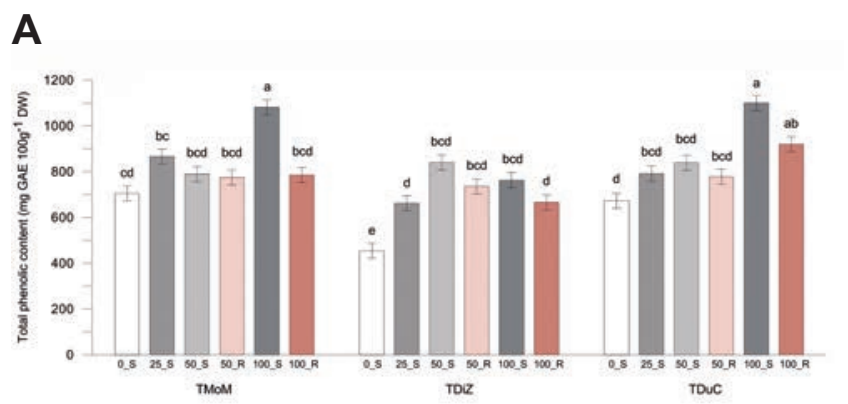

B

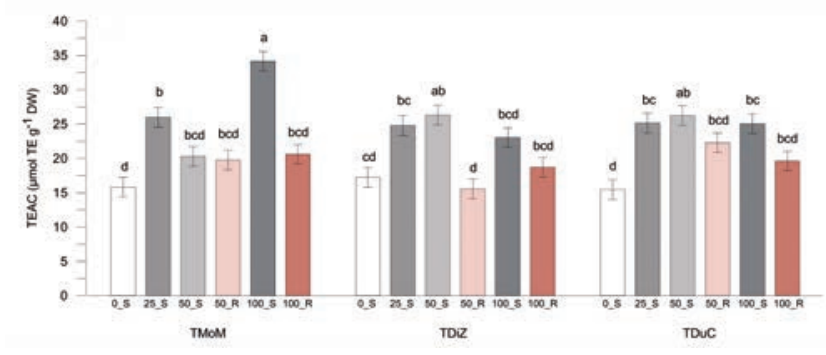

Figure 3. Total polyphenols content (mg gallic acid equivalent, GAE, $100 \mathrm{~g}^{-1}$ dry weight, DW) (A) and antiradical activity (TEAC, $\mu$ mol Trolox equivalents, TE, $\mathrm{g}^{-1} \mathrm{DW}$ ) (B) in wheatgrass of T. monococcum cv Monlis (TMoM), T. dicoccum cv Zefiro (TDiZ), and T. durum cv Creso (TDuC), obtained under 0 (i.e. control), 25, 50 and $100 \mathrm{mM} \mathrm{NaCl}$ solutions (0_S, 25_S, 50_S and 100_S, respectively) throughout the whole experiment (i.e. until wheatgrass stage), or under 50 and $100 \mathrm{mM} \mathrm{NaCl}$ solutions until sprout stage and then transferred to $0 \mathrm{mM}$ until wheatgrass stage (recovery-treatments: 50_R and 100_R, respectively). Data represent means \pm standard errors, $\mathrm{n}=2$ independent replicates. Different letters stand for statistically significant differences at $\mathbf{P}<0.05$ (Tukey's honestly significant difference test).
Casals and Cisneros-Zevallos, 2010; Dueñas et al., 2009). Germination leads to significant changes in phenolic composition, mainly due to the activation of endogenous hydrolytic enzymes, which in turn affect the antiradical activity of sprouts (Dueñas et al., 2009).

Modifications of sprouting conditions (i.e. salt-stress during germination) aimed at overproducing antioxidants inter alia phenolic compounds, usually involve induction of the natural mechanisms of plant resistance. In our study, the interaction Genotype $x$ $\mathrm{NaCl}$ was significant in terms of total polyphenols contents in sprouts and wheatgrass of TMoM, TDiZ and TDuC $(\mathrm{P}<0.05$; Figures $2 \mathrm{~A}$ and $3 \mathrm{~A}$, respectively). A similar genotype-specific response to different magnitudes of salt stress was also observed by Danai-Tambhale et al. (2011) in 21-day old seedling of two indica rice cultivars, indicating the importance of genetic variability on salt tolerance (Yuan et al., 2010). In general, sprouts of TMoM did not shown differences on TPC values when exposed to different salinity conditions; moreover, at wheatgrass growth stage TPC values were significantly higher only at $100 \mathrm{mM} \mathrm{NaCl}$ solution (1082 mg GAE $100 \mathrm{~g}^{-1} \mathrm{DW}$; Figure 3A). This trend is in
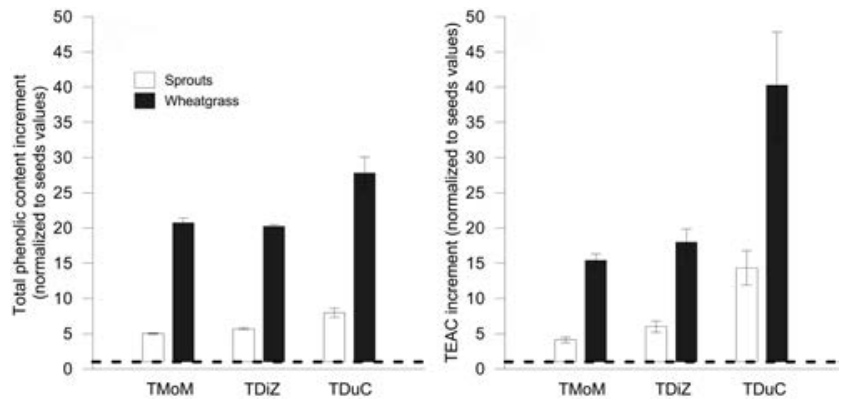

Figure 4. Increment normalised to grains values (dashed line) of total polyphenols content (mg gallic acid equivalent $100 \mathrm{~g}^{-1}$ dry weight, DW) (A) and antiradical activity (TEAC, $\mu$ mol Trolox equivalents $\mathrm{g}^{-1} \mathrm{DW}$ (B) as observed in T. monococcum cv Monlis (TMoM), T. dicoccum cv Zefiro (TDiZ), and T. durum cv Creso $(\mathrm{TDuC})$ during germination, averaged over salt treatments. See Table 1 and text for further explaining. Data represent means \pm standard errors, $\mathrm{n}=2$ independent replicates.

Table 2. Free and bound phenolic acids content (both $\mu \mathrm{g} \mathrm{g}^{-1}$ dry weight) in grains of $T$. monococcum $\mathrm{cv}$ Monlis, $T$. dicoccum $\mathrm{cv}$ Zefiro, and T. durum cv Creso.

\begin{tabular}{|c|c|c|c|c|c|c|c|}
\hline \multirow[t]{2}{*}{ Genotypes } & & \multicolumn{5}{|c|}{ PAs ( $\left.\mu g g^{-1} D W\right)$} & \multirow[b]{2}{*}{ Total $^{\circ}$} \\
\hline & & $\mathrm{CA}$ & SRA & P-CA & trans-FA & SA & \\
\hline \multirow[t]{5}{*}{ Free-PAs } & TMoM & nd & nd & $1.74^{\mathrm{b}}$ & $1.43^{\mathrm{ab}}$ & nd & $3.17^{\mathrm{a}}$ \\
\hline & TDiZ & nd & nd & $2.09^{\mathrm{a}}$ & $1.61^{\mathrm{a}}$ & nd & $3.70^{\mathrm{a}}$ \\
\hline & $\mathrm{TDuC}$ & nd & nd & $0.40^{c}$ & $1.25^{\mathrm{b}}$ & nd & $1.65^{\mathrm{b}}$ \\
\hline & Significance & & & $* *$ & $*$ & & $* *$ \\
\hline & SED & & & 0.06 & 0.07 & & 0.11 \\
\hline \multirow[t]{5}{*}{ Bound-PAs } & TMoM & 17.96 & $3.99^{\mathrm{b}}$ & $541.35^{\mathrm{a}}$ & $729.80^{\mathrm{a}}$ & 47.07 & $1340.17^{\mathrm{a}}$ \\
\hline & TDiZ & 14.63 & $5.14^{\mathrm{a}}$ & $529.56^{\mathrm{a}}$ & $673.51^{\mathrm{a}}$ & nd & $1222.85^{\mathrm{b}}$ \\
\hline & TDuC & 13.00 & nd & $13.90^{\mathrm{b}}$ & $316.99^{b}$ & nd & $343.89^{c}$ \\
\hline & Significance & ns & $* *$ & $* *$ & $* *$ & - & $* *$ \\
\hline & SED & 11.08 & 0.41 & 8.13 & 29.62 & - & 26.95 \\
\hline
\end{tabular}

PAs, phenolic acids; DW, dry weight; CA, caffeic acid; SRA, syringic acid; P-CA, P-coumaric acid; trans-FA, trans-ferulic acid; SA, salicylic acid; TMoM, Triticum monococcum cv Monlis; TDiZ, Triticum. dicoccum cv Zefiro; TDuC, Triticum durum cv Creso; SED, standard error of differences between means; nd, not detectable. ${ }^{*} \mathrm{P}<0.05$; ${ }^{* *} \mathrm{P}<0.01$; ns, not-significant. ${ }^{\circ}$ Sum of all detected PAs. Degrees of freedom: Genotype 2; residual 3 . a-cDifferent letters stand for statistically significant differences at $\mathrm{P}<0.05$ (Tukey's honestly significant difference). 
agreement with the studies of Guo et al. (2014) and Yuan et al. (2010) who found a significant increase in TPC in radish and broccoli sprouts, but only at the highest stressful condition. Conversely, the effect of salt stress significantly enhanced TPC of both TDiZ and TDuC genotypes already during the very early stages (Figure 2A) and the highest values were reached by 25 S treatments $(295$ and $274 \mathrm{mg} \mathrm{GAE} 100 \mathrm{~g}^{-1} \mathrm{DW}$, in TDiZ and TDuC, respectively). For these genotypes, at the highest salt concentration (100_S treatment) the TPC levels were similar to the unstressed control (Figure 2A). The prolonged exposure to salinity, as observed at wheatgrass stage, enhanced TPC values in TDuC up to 100_S treatment (Figure 3A); no differences between salt-treatments were observed in TDiZ (Figure 3A). Regardless of genotypes, recovery-treatments lead to a reduction on TPC, especially for those previously subjected to the highest stressful condition; however, it has to be pointed out that TPC values in 50_R and 100_R treatments were generally higher than in the unstressed control (Figure 3A).

The trend of the radical scavenging activity, as a function of salt stress levels, resulted often unclear and not always in agreement with TPC data, strictly depending on growth stage and genotypes; for this reason it does not seem meaningful and worth speculating on. Anyway, averaged over genotypes, we found a signifi- cant linear correlation between TPC and TEAC values at sprout stage $\left(r^{2}=0.81\right)$, which was reduced at wheatgrass stage $\left(r^{2}=0.72\right)$.

\section{Effect of sprouting and salt stress on free- and bound- phenolic acids}

Both free and bound fractions content of the detected PAs in sprouts and wheatgrass of TMoM, TDiZ and TDuC are presented in Tables 3 and 4, respectively.

The total free-PAs content ranged from 10.5 to $27.2 \mu \mathrm{g} \mathrm{g}^{-1} \mathrm{DW}$ in sprouts (Table 3 ) and from 18.4 to $85.8 \mu \mathrm{g} \mathrm{g}^{-1} \mathrm{DW}$ in wheatgrass (Table 4). During germination the total free-PAs content increased significantly by over 6-fold at sprout stage (averaged over genotypes and salt treatments) (Figure 5A). Then, a further increase from sprout to wheatgrass stage was observed and the free-PAs content averagely increased by about 17 -fold with respect to grains (Figure 5A), confirming results on a FW basis reported by Benincasa et al. (2015). Genotypes gave different response to germination process with the highest free-PAs increase observed in $\mathrm{TDuC}$.

Total bound PAs ranged from 334.2 to $1898.8 \mu \mathrm{g} \mathrm{g}^{-1} \mathrm{DW}$ in sprouts (Table 3) and from 208.0 to $7769.8 \mu \mathrm{g} \mathrm{g}^{-1} \mathrm{DW}$ in wheat-

Table 3. Free and bound phenolic acids content (both $\mu \mathrm{g} \mathrm{g}^{-1}$ dry weight) in sprouts of T. monococcum cv Monlis, T. dicoccum cv Zefiro, and T. durum cv Creso, obtained under 0 (i.e. control), 25, 50 and $100 \mathrm{mM} \mathrm{NaCl}$ solutions.

\begin{tabular}{|c|c|c|c|c|c|c|c|c|c|}
\hline \multicolumn{4}{|l|}{ Genotypes } & \multicolumn{5}{|c|}{ PAs ( $\left.\mu g g^{-1} \mathrm{DW}\right)$} & \multirow[b]{2}{*}{$\operatorname{Total}^{\circ}$} \\
\hline & & & & CA & SRA & P-CA & trans-FA & SA & \\
\hline \multirow[t]{16}{*}{ Free-PAs } & \multirow[t]{4}{*}{ TMoM } & 0_S & & nd & nd & $5.1^{\mathrm{cd}}$ & $12.8^{\mathrm{bc}}$ & nd & $17.9^{\mathrm{cd}}$ \\
\hline & & $2 \overline{5} \_\mathrm{S}$ & & nd & nd & $5.3^{\mathrm{cd}}$ & $21.9^{\mathrm{a}}$ & nd & $27.2^{\mathrm{a}}$ \\
\hline & & 50_S & & nd & nd & $6.2^{\mathrm{bcd}}$ & $14.0^{\mathrm{bc}}$ & nd & $20.2^{\mathrm{bc}}$ \\
\hline & & $100 \_\mathrm{S}$ & & nd & nd & $4.1^{\mathrm{d}}$ & $13.6^{\mathrm{bc}}$ & nd & $17.7^{\mathrm{cd}}$ \\
\hline & \multirow[t]{4}{*}{ TDiZ } & $0 \mathrm{~S}^{-}$ & & nd & nd & $7.8^{\mathrm{abc}}$ & $9.8^{\text {cde }}$ & nd & $17.6^{\mathrm{cd}}$ \\
\hline & & $2 \overline{5} \_\mathrm{S}$ & & nd & nd & $6.9^{b c d}$ & $17.7^{\mathrm{ab}}$ & nd & $24.6^{\mathrm{ab}}$ \\
\hline & & 50_S & & nd & nd & $8.7^{\mathrm{ab}}$ & $13.8^{b c}$ & nd & $22.5^{\mathrm{abc}}$ \\
\hline & & $100 \mathrm{~S}$ & & nd & nd & $5.6^{\mathrm{bcd}}$ & $7.2^{\text {de }}$ & nd & $12.8^{\mathrm{de}}$ \\
\hline & \multirow[t]{8}{*}{$\mathrm{TDuC}$} & $0 \_S$ & & nd & nd & $5.4^{\mathrm{cd}}$ & $5.1^{\mathrm{e}}$ & nd & $10.5^{\mathrm{e}}$ \\
\hline & & $2 \overline{5} \_\mathrm{S}$ & & nd & nd & $7.3^{\mathrm{bc}}$ & $13.0^{\mathrm{bc}}$ & nd & $20.3^{b c}$ \\
\hline & & 50_S & & nd & nd & $10.7^{\mathrm{a}}$ & $12.9 \mathrm{bc}$ & nd & $23.6^{\mathrm{ab}}$ \\
\hline & & $100 \_S$ & & nd & nd & $10.9^{\mathrm{a}}$ & $11.8^{\mathrm{cd}}$ & nd & $22.6^{\mathrm{abc}}$ \\
\hline & & Significance & Genotype & & & $* *$ & $* *$ & & ns \\
\hline & & & $\mathrm{NaCl}$ & & & $* *$ & $* *$ & & $* *$ \\
\hline & & & Genotype x $\mathrm{NaCl}$ & & & $* *$ & $* *$ & & $* *$ \\
\hline & & SED & & & 0.81 & 1.31 & & 1.42 & \\
\hline \multirow[t]{16}{*}{ Bound-PAs } & \multirow[t]{4}{*}{ TMoM } & 0_S & nd & nd & $410.8^{\mathrm{de}}$ & $410.5^{\mathrm{de}}$ & 21.1 & $842.5^{\mathrm{ef}}$ & \\
\hline & & $2 \overline{5} \_\mathrm{S}$ & nd & nd & $641.4^{b}$ & $757.4^{b}$ & 27.6 & $1426.5^{b c}$ & \\
\hline & & 50_S & nd & nd & $881.0^{\mathrm{a}}$ & $979.5^{\mathrm{a}}$ & 38.1 & $1898.8^{\mathrm{a}}$ & \\
\hline & & $100 \_\mathrm{S}$ & nd & nd & $356.7^{\mathrm{de}}$ & $366.0^{\text {def }}$ & 15.9 & $738.8^{f}$ & \\
\hline & \multirow[t]{4}{*}{ TDiZ } & 0_S & & nd & nd & $477.7^{\mathrm{cd}}$ & $562.4^{\mathrm{bcd}}$ & 23.7 & $1063.8^{d}$ \\
\hline & & $2 \overline{5} \_\mathrm{S}$ & & nd & nd & $583.9^{\mathrm{bc}}$ & $744.2^{\mathrm{b}}$ & 35.2 & $1363.4^{c}$ \\
\hline & & 50_S & & nd & nd & $676.0^{\mathrm{b}}$ & $749.1^{\mathrm{b}}$ & 68.8 & $1494.0^{\mathrm{bc}}$ \\
\hline & & $100 \_\mathrm{S}$ & & nd & nd & $141.1^{\mathrm{f}}$ & $161.7^{\mathrm{f}}$ & 31.4 & $334.2^{\mathrm{g}}$ \\
\hline & \multirow[t]{8}{*}{$\mathrm{TDuC}$} & $0 \_S$ & & 63.0 & nd & $468.4^{\mathrm{cd}}$ & $1056.9^{a}$ & nd & $1588.4^{b}$ \\
\hline & & $2 \overline{5} \_\mathrm{S}$ & & 32.6 & nd & $291.8 \mathrm{e}$ & $654.7^{\mathrm{bc}}$ & nd & $979.1^{\mathrm{de}}$ \\
\hline & & 50_S & & 33.9 & nd & $104.4^{\mathrm{f}}$ & $522.3^{\mathrm{cd}}$ & nd & $660.7^{f}$ \\
\hline & & $100 \_\mathrm{S}$ & & 32.9 & nd & $74.8^{f}$ & $229.6^{\mathrm{ef}}$ & nd & $337.5^{\mathrm{g}}$ \\
\hline & & Significance & Genotype & & & $* *$ & $*$ & & $* *$ \\
\hline & & & $\mathrm{NaCl}$ & & & $* *$ & $* *$ & & $* *$ \\
\hline & & & Genotype x $\mathrm{NaCl}$ & & & $* *$ & $* *$ & & $* *$ \\
\hline & & SED & & & & 33.44 & 54.37 & & 48.09 \\
\hline
\end{tabular}

PA, phenolic acid; DW, dry weight; CA, caffeic acid; SRA, syringic acid; P-CA, P-coumaric acid; trans-FA, trans-ferulic acid; SA, salicylic acid; TMoM, T. monococcum cv Monlis; TDiZ, T. dicoccum cv Zefiro; TDuC, T. durum cv Creso; SED, standard error of differences between means; nd, not detectable. ${ }^{*} \mathrm{P}<0.05 ;{ }^{* *} \mathrm{P}<0.01$; ns, not significant. ${ }^{\circ}$ Sum of all detected PAs. Degrees of freedom: Genotype 2 ; NaCl 3 ; Genotype x NaCl 6 ; residual12. Data are the means for $n=2$ independent replicates. ${ }^{a-g}$ Different letters stand for statistically significant differences at $\mathrm{P}<0.05$ (Tukey's honestly significant difference). 
grass (Table 4), contributing heavily to the total detected PAs (freePAs plus bound-PAs). Also in this case, bound-PAs content tended to increase over germination although not at the same extent as the free- ones, from 0.5 -fold to about 2.5 -fold in sprouts and wheatgrass, respectively (averaged over genotypes and salt treatments) (Figure 5B).

The effect of genotype was particularly clear: in TMoM and TDiZ the content of total-bound PAs were lower at sprout stage with respect to grains (Figure $5 \mathrm{~B}$ ). An early reduction in the TPC of bound phenolic extracts was also observed by Hung et al. (2012) in waxy wheat germinated grains, and it was attributed to a first lost hydrolysis of polyphenolic compounds bound to cell walls (Yang et al., 2001). Moreover, during the first stages of germination the decline of bound phenolic concentration coincided with a rise of the free-fraction, indicating a shift between two forms (Xu et al., 2009). However, it is improbable to compare our results with the literature because of the different germination time (5-days vs 2-days old sprouts).

HPLC analyses showed that the qualitative compositions of the free- and bound- phenolic fractions of TMoM, TDiZ and TDuC during germination did not substantially change (Tables 2, 3 and 4). In sprouts, trans-FA contributed to $63 \%$ and $57 \%$ of the total freePAs and bound-PAs, respectively (Table 3 ). The trans-FA was also the most represented PA in wheatgrass $(65 \%$ of the total free-PAs and $64 \%$ of the total bound-PAs; Table 4) (Hung et al., 2011).

Both free- and bound-PAs fractions in sprouts extracts were significantly affected by Genotype $x \mathrm{NaCl}$ interaction $(\mathrm{P}<0.05$; Table 3). In TMoM sprouts, salt-stress induced significant differences in terms of total free-PAs only at 25 S, in part confirming TPC data. However, salinity significantly enhanced total boundPAs (highest value at 50_S; Table3). Interestingly, the increase in the bound-fraction was related to a significant induction of both PCA and trans-FA. Cell-wall-bound FA has been demonstrated to cope with drought tolerance in triticale seedlings, acting as regulator of cell growth by ester and decreasing cell-wall extensibility and sprout elongation at the cost of osmotic adjustment (Hura et al., 2009). Conversely, salt-stress raised up total free-PAs till $50 \mathrm{~S}$ in sprouts of $\mathrm{TDuC}$, whilst significantly lowered total bound-PAs (Table 3). The negative variation of total bound-PAs mainly depended on the variation of both P-CA and trans-FA. In general, salt-stress treatment induced an increase in the concentration of both free- and bound-phenolic fractions in sprouts extracts of TDiZ, although the differences were not always significant (Table 3). The contribution to total bound-PAs increase is also attributable to SA, which showed the highest values in 50_S treatment (Table 3) and which could act as a signaling molecule inducing salt tolerance in plants (Jayakannan et al., 2015).

With respect to wheatgrass extracts, the content of total freePAs in response to $\mathrm{NaCl}$ treatments showed similar trends to sprouts ones, although differences on specific PAs were observed (Table 4). Regarding the bound-fraction, total detected bound-PAs in TMoM showed an upward trend until 50_S treatment; further $\mathrm{NaCl}$ level significantly constrained total bound-PAs values (Table 4). The same trend was observed for P-CA and trans-FA. However, the recovery-treatment $100 \_\mathrm{R}$ allowed increasing total bound-PAs with respect to $100 \_\mathrm{S}$, thanks to the contribution of trans-FA and $\mathrm{SA}$ in their bound forms (Table 4). Interesting, SA became detectable in its bound form also in 50_R and 100_R treatments (Table 4). We hypothesised that TMoM, given optimal growing conditions, is promptly adaptable to stressful levels during germination with SA being involved in this process. On the other hand, in TDuC P-CA, trans-FA and, consequently, total-PAs in their bound forms significantly decreased in response to prolonged saltstress treatments (Table 4). For TDiZ, despite an increase in total bound-PAs until $50 \mathrm{~S}$, any significant difference was detected (Table 4). This could be attributable also to the reduction of bound SRA that became undetectable under severe stressful conditions, even if the optimal growing conditions were restored (see 50_R and $100 \mathrm{R}$ treatments; Table 4). Interestingly, TDiZ represented the genotype characterised by higher SA content with respect to TMoM and TDuC (Table 4).
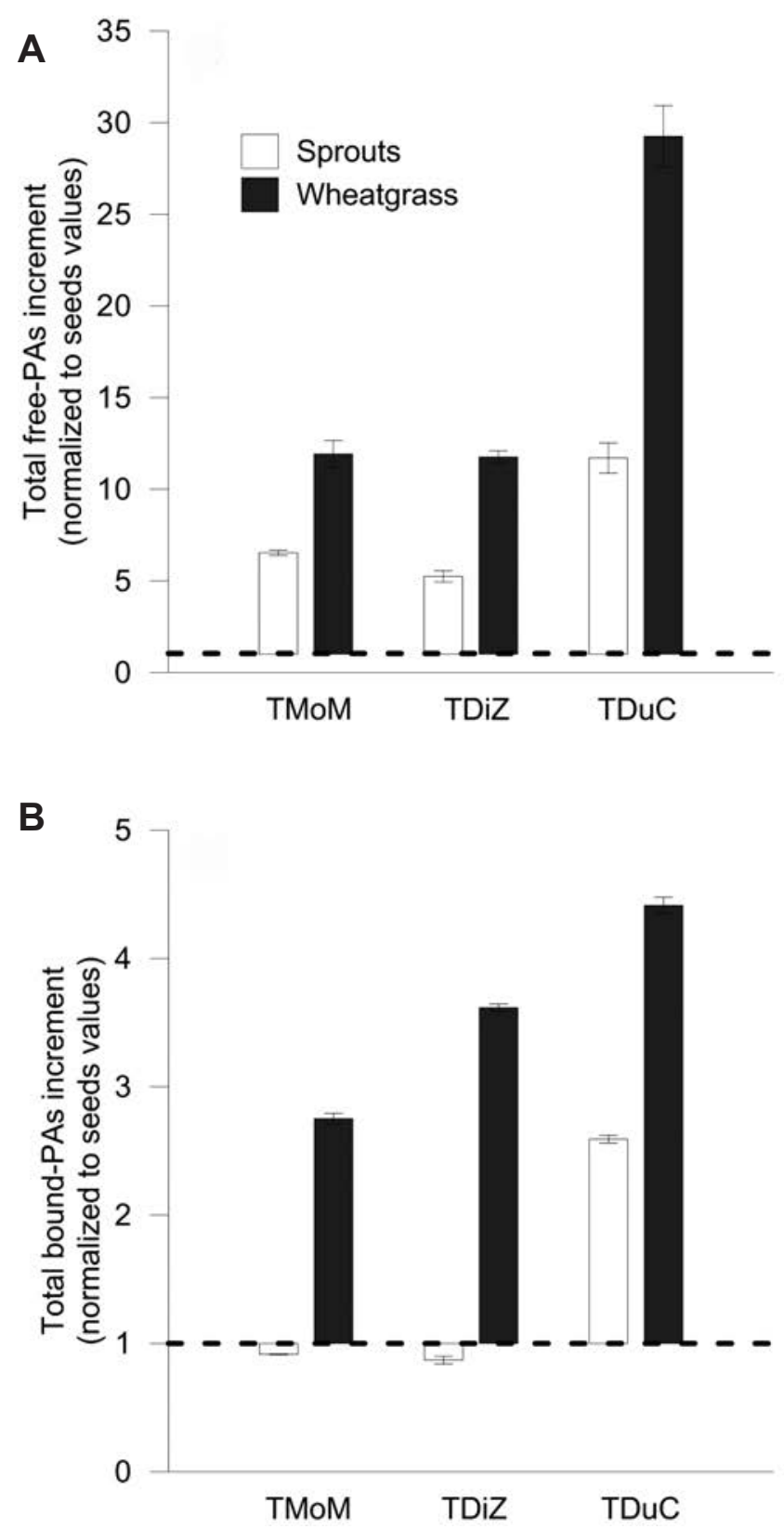

Figure 5. Increment normalised to grains values (dashed line) of total free-phenolic acids (PAs) ( $\mu \mathrm{g} \mathrm{g}^{-1}$ dry weight, DW) (A) and total bound-PAs ( $\mu \mathrm{g} \mathrm{g}^{-1} \mathrm{DW}$ ) (B) in T. monococcum cv Monlis (TMoM), T. dicoccum cv Zefiro (TDiZ), and T. durum cv Creso $(\mathrm{TDuC})$ during germination, averaged over salt treatments. See Table 1 and text for further explanation. Data represent means \pm standard errors, $\mathrm{n}=\mathbf{2}$ independent replicates. 


\section{Conclusions}

Sprouting significantly enhanced TPC and detected boundand free-PAs, regardless of genotype. Response to salt stress depended on genotype sensitivity, growth stage and salt concentration. In general, moderate salinity levels (not exceeding $50 \mathrm{mM}$ $\mathrm{NaCl}$ solution) induced accumulation of phenolic acids in both sprouts and wheatgrass of Triticum genotypes with a pronounced variability. In particular, in TMoM the bound-PAs fraction of both sprout and wheatgrass extracts increased until the dose of $50 \mathrm{mM}$ $\mathrm{NaCl}$, probably thanks to the induction of P-CA and trans-FA. Conversely, in $\mathrm{TDuC}, \mathrm{NaCl}$ determined an increase of PAs in their free form (as confirmed by TPC data) and a reduction of the bound ones. In TDiZ salinity generally enhanced the TPC, TEAC, freePAs and bound-PAs content, although the responses were not always significant.

However, to better understand the species-specific response to salt, further researches on a wider number of both genotypes and growing environments, are needed.

Table 4. Free and bound phenolic acids content (both $\mu \mathrm{g} \mathrm{g}^{-1}$ dry weight) as observed in wheatgrass of T. monococcum cv Monlis, T. dicoccum cv Zefiro, and T. durum cv Creso, obtained with 0 (i.e. control), 25, 50 and $100 \mathrm{mM} \mathrm{NaCl}$ solutions throughout the whole experiment (i.e. until wheatgrass stage), or with 50 and $100 \mathrm{mM} \mathrm{NaCl}$ solutions until sprout stage and then transferred to $0 \mathrm{mM} \mathrm{NaCl}$ until wheatgrass stage.

\begin{tabular}{|c|c|c|c|c|c|c|c|c|c|}
\hline \multicolumn{4}{|c|}{ Genotypes } & \multicolumn{6}{|c|}{ PAs ( $\left.\mu g g^{-1} D W\right)$} \\
\hline & & & & CA & SRA & $\mathrm{P}-\mathrm{CA}$ & trans-FA & SA & Total $^{\circ}$ \\
\hline \multirow{22}{*}{ Free-PAs } & \multirow[t]{6}{*}{ TMoM } & 0_S & & nd & nd & $6.0^{\mathrm{de}}$ & $36.3^{\mathrm{bcd}}$ & nd & $42.3^{\mathrm{bcd}}$ \\
\hline & & $25 \_\mathrm{S}$ & & nd & nd & $5.2^{\mathrm{de}}$ & $26.1^{\text {def }}$ & nd & $31.3^{\mathrm{d}}$ \\
\hline & & 50_S & & nd & nd & $5.2^{\mathrm{de}}$ & $32.1^{\text {bcde }}$ & nd & $37.3^{\mathrm{cd}}$ \\
\hline & & 50_R & & nd & 2.3 & $10.1^{\text {bcde }}$ & $16.6^{\mathrm{ef}}$ & nd & $28.9 \mathrm{~d}$ \\
\hline & & $100 \_S$ & & nd & nd & $2.7^{\mathrm{e}}$ & $19.0^{\mathrm{ef}}$ & nd & $21.7^{\mathrm{d}}$ \\
\hline & & $100 \_\mathrm{R}$ & & 8.7 & 9.4 & $14.9^{\mathrm{bc}}$ & $32.3^{\text {bcde }}$ & nd & $65.3^{\mathrm{ab}}$ \\
\hline & \multirow[t]{6}{*}{ TDiZ } & $0 \_S$ & & nd & nd & $15.9^{\mathrm{b}}$ & $19.1^{\mathrm{ef}}$ & nd & $35.0^{\mathrm{d}}$ \\
\hline & & $2 \overline{5} \_\mathrm{S}$ & & nd & nd & $11.4^{\mathrm{bcd}}$ & $17.0^{\mathrm{ef}}$ & nd & $28.4^{\mathrm{d}}$ \\
\hline & & 50_S & & nd & nd & $14.9^{\mathrm{bc}}$ & $58.1^{\mathrm{a}}$ & nd & $73.0^{\mathrm{a}}$ \\
\hline & & 50_R & & nd & nd & $16.8^{\mathrm{b}}$ & $45.0^{\mathrm{abc}}$ & nd & $61.8^{\mathrm{abc}}$ \\
\hline & & $100 \_\mathrm{S}$ & & nd & nd & $7.6^{\text {cde }}$ & $18.9^{\mathrm{ef}}$ & nd & $26.5^{\mathrm{d}}$ \\
\hline & & $100 \_R$ & & nd & nd & $11.6^{\mathrm{bcd}}$ & $24.7^{\text {def }}$ & nd & $36.3^{\text {cd }}$ \\
\hline & \multirow{10}{*}{$\mathrm{TDuC}$} & $0 \_S$ & & nd & nd & $28.7^{\mathrm{a}}$ & $27.0^{\text {def }}$ & 22.9 & $78.6^{\mathrm{a}}$ \\
\hline & & $2 \overline{5} \_\mathrm{S}$ & & nd & nd & $13.1^{\mathrm{bcd}}$ & $29.0^{\text {cdef }}$ & nd & $42.1^{\mathrm{bcd}}$ \\
\hline & & 50_S & & nd & nd & $33.0^{\mathrm{a}}$ & $46.8^{\mathrm{ab}}$ & 5.96 & $85.8^{\mathrm{a}}$ \\
\hline & & 50_R & & nd & nd & $5.8^{\mathrm{de}}$ & $12.6^{\mathrm{f}}$ & nd & $18.4^{\mathrm{d}}$ \\
\hline & & $100 \_S$ & & nd & nd & $26.1^{\mathrm{a}}$ & $13.5^{\mathrm{f}}$ & nd & $39.6^{\mathrm{bcd}}$ \\
\hline & & $100 \_\mathrm{R}$ & & nd & nd & $11.3^{\mathrm{bcd}}$ & $14.5^{\mathrm{f}}$ & nd & $25.8^{\mathrm{d}}$ \\
\hline & & Significance & Genotype & & & $* *$ & $* *$ & & $* *$ \\
\hline & & & $\mathrm{NaCl}$ & & & $* *$ & $* *$ & & $* *$ \\
\hline & & & Genotype x $\mathrm{NaCl}$ & & & $* *$ & $* *$ & & $* *$ \\
\hline & & SED & & & 1.99 & 4.08 & & 6.44 & \\
\hline \multirow{22}{*}{ Bound-PAs } & \multirow{6}{*}{ TMoM } & 0_S & & nd & nd & $1688.8^{c}$ & $2250.7^{\mathrm{d}}$ & nd & $3939.4^{\text {cd }}$ \\
\hline & & $2 \overline{5} \_\mathrm{S}$ & & nd & nd & $1971.5^{b}$ & $2353.5^{\mathrm{cd}}$ & nd & $4325.0^{\text {bcd }}$ \\
\hline & & 50_S & & nd & nd & $2150.7^{\mathrm{b}}$ & $2711.8^{c}$ & nd & $4862.5^{b}$ \\
\hline & & 50_R & & nd & nd & $1525.0^{\mathrm{bc}}$ & $2702.7^{c}$ & 177.2 & $4404.9 \mathrm{bc}$ \\
\hline & & $100 \_S$ & & nd & nd & 579.9 def & $519.0^{\mathrm{gh}}$ & nd & $1098.9^{f}$ \\
\hline & & 100_R & & nd & nd & $929.5^{\text {cde }}$ & $2477.6^{\mathrm{cd}}$ & 95.6 & $3502.7^{\mathrm{d}}$ \\
\hline & \multirow[t]{6}{*}{ TDiZ } & $0 \_S$ & & nd & 26.9 & $3416.8^{\mathrm{a}}$ & $3726.6^{\mathrm{a}}$ & 248.7 & $7419.1^{\mathrm{a}}$ \\
\hline & & 25 & & nd & 43.0 & $3521.4^{\mathrm{a}}$ & $3792.6^{\mathrm{a}}$ & 228.1 & $7585.1^{\mathrm{a}}$ \\
\hline & & 50_S & & nd & 22.9 & $3779.5^{\mathrm{a}}$ & $3761.5^{\mathrm{a}}$ & 205.9 & $7769.8^{\mathrm{a}}$ \\
\hline & & 50_R & & nd & nd & $288.4^{\text {def }}$ & $1572.4^{\mathrm{e}}$ & 155.6 & $2016.4^{\mathrm{e}}$ \\
\hline & & $100 \_S$ & & nd & nd & $427.4^{\text {def }}$ & $488.2^{\mathrm{gh}}$ & 52.3 & $967.8^{f g}$ \\
\hline & & 100_R & & nd & nd & $159.4^{\mathrm{ef}}$ & $553.7^{\mathrm{g}}$ & 73.3 & $786.3^{\mathrm{fg}}$ \\
\hline & \multirow[t]{10}{*}{ TDuC } & $0 \_S$ & & nd & 19.0 & $1045.9^{c d}$ & $3138.6^{\mathrm{b}}$ & nd & $4203.5^{\mathrm{bcd}}$ \\
\hline & & $2 \overline{5} \_\mathrm{S}$ & & nd & 2.1 & $308.8^{\text {def }}$ & $956.0^{\mathrm{f}}$ & nd & $1266.9^{\mathrm{ef}}$ \\
\hline & & 50_S & & nd & nd & $246.4^{\mathrm{ef}}$ & $1137.7^{\mathrm{f}}$ & nd & $1384.1^{\text {ef }}$ \\
\hline & & 50_R & & nd & nd & $177.8^{\text {ef }}$ & $1213.2^{\text {ef }}$ & nd & $1391.1^{\text {ef }}$ \\
\hline & & $100 \_S$ & & nd & nd & $162.3^{\text {ef }}$ & $488.9^{\mathrm{gh}}$ & nd & $651.3^{\mathrm{fg}}$ \\
\hline & & $100 \_\mathrm{R}$ & & nd & nd & $63.9^{f}$ & $144.1^{\mathrm{h}}$ & nd & $208.0^{\mathrm{g}}$ \\
\hline & & Significance & Genotype & & & $* *$ & $* *$ & & $* *$ \\
\hline & & & $\mathrm{NaCl}$ & & & $* *$ & $* *$ & & $* *$ \\
\hline & & & Genotype x $\mathrm{NaCl}$ & & & $* *$ & $* *$ & & $* *$ \\
\hline & & SED & & & 198.74 & 96.88 & & 217.90 & \\
\hline
\end{tabular}

PA, phenolic acid; DW, dry weight; CA, caffeic acid; SRA, syringic acid; P-CA, P-coumaric acid; trans-FA, trans-ferulic acid; SA, salicylic acid; TMoM, Triticum. monococcum cv Monlis; TDiZ, Triticum dicoccum cv Zefiro; TDuC, Triticum durum cv Creso; SED, standard error of differences between means; nd, not detectable. ${ }^{* *} \mathrm{P}<0.01$. ${ }^{\circ}$ Sum of all detected PAs. Degrees of freedom: Genotype2; NaCl 5; Genotype x NaCl 10; residual18. Data are the means for $\mathrm{n}=2$ independent replicates. ${ }^{\mathrm{a}-\mathrm{h}}$ Different letters stand for statistically significant differences at $\mathrm{P}<0.05$ (Tukey's honestly significant difference). 
These results indicate that salt stress could be efficiently modulated in order to improve the nutritional value of cereal sprouts and wheatgrass, through the accumulation of their bioactive compounds. This could provide the basis for further in vivo investigations to understand the impact of the enriched-quality sproutsbased products on human health.

\section{References}

Benincasa P, Galieni A, Manetta AC, Pace R, Guiducci M, Pisante M, Stagnari F, 2015. Phenolic compounds in grains, sprouts and wheatgrass of hulled and non-hulled wheat species. J. Sci. Food Agr. 95:1795-803.

Cevallos-Casals BA, Cisneros-Zevallos L, 2010. Impact of germination on phenolic content and antioxidant activity of 13 edible seed species. Food Chem. 119:1485-90.

Danai-Tambhale S, Kumar V, Shriram V, 2011. Differential response of two scented indica rice (Oryza sativa) cultivars under salt stress. J. Stress Physiol. Biochem. 7:387-97.

Datta JK, Nag S, Banerjee A, Mondai NK, 2009. Impact of salt stress on five varieties of wheat (Triticum aestivum L.) cultivars under laboratory condition. J. Appl. Sci. Environ. Manag. 13:93-7.

Dinelli G, Segura-Carretero A, Di Silvestro R, Marotti I, ArreazRoman D, Benedettelli S, Ghiselli L, Fernandez-Gutierrez A, 2011. Profiles of phenolic compounds in modern and old common wheat varieties determined by liquid chromatography coupled with time-of-flight mass spectrometry. J. Chromatogr. A 1218:7670-81.

Donkor ON, Stojanovska L, Ginn P, Ashton J, Vasiljevic T, 2012. Germinated grains - sources of bioactive compounds. Food Chem. 135:950-9.

Dueñas M, Hernández T, Estrella I, Fernández D, 2009. Germination as a process to increase the polyphenol content and antioxidant activity of lupin seeds (Lupinus angustifolius L.). Food Chem. 117:599-607.

Gawlik-Dziki U, Świeca M, Dziki D, 2012. Comparison of phenolic acids profile and antioxidant potential of six varieties of spelt (Triticum spelta L.). J. Agr. Food Chem. 60:4603-12.

Gorinstein S, Vargas OJM, Jaramillo NO, Salas IA, Ayala ALM, Arancibia-Avila P, Toledo F, Katrich E, Trakhtenberg S, 2007. The total polyphenols and the antioxidant potentials of some selected cereals and pseudocereals. Eur. Food Res. Technol. 225:321-8.

Guo L, Yang R, Wang Z, Guo Q, Gu Z, 2014. Effect of NaCl stress on health-promoting compounds and antioxidant activity in the sprouts of three broccoli cultivars. Int. J. Food Sci. Nutr. 65:476-81.

Herbinger K, Tausz M, Wonisch A, Soja G, Sorger A, Grill D, 2002. Complex interactive effects of drought and ozone stress on the antioxidant defense systems of two wheat cultivars. Plant Physiol. Biochem. 40:691-6.

Hung P, Hatcher DW, Barker W, 2011. Phenolic acid composition of sprouted wheats by ultra-performance liquid chromatography (UPLC) and their antioxidant activities. Food Chem. 126:1896-901.

Hung PV, Maeda T, Yamamoto S, Morita N, 2012. Effects of germination on nutritional composition of waxy wheat. J.Sci. Food Agr. 92:667-72.

Hura T, Hura K, Grzesiak S, 2009. Possible contribution of cellwall-bound ferulic acid in drought resistance and recovery in triticale seedlings. J. Plant Physiol. 166:1720-33.
Jayakannan M, Bose J, Babourina O, Shabala S, Massart A, Poschenrieder C, Rengel Z, 2015. The NPR1-dependent salicylic acid signalling pathway is pivotal for enhanced salt and oxidative stress tolerance in Arabidopsis. J. Exp. Bot. 66:1865-75.

Kavas M, Akça OE, Akçay UC, Peksel B, Eroğlu S, Öktem HA, Yücel M, 2015. Antioxidant responses of peanut (Arachis hypogaea L.) seedlings to prolonged salt-induced stress. Arch. Biol. Sci. 67:1303-12.

Kim KH, Tsao R, Yang R, Cui SW, 2006. Phenolic acid profiles and antioxidant activities of wheatbran extracts and the effect of hydrolysis conditions. Food Chem. 95:466-73.

Kugler F, Sintzing F, Carle R, 2007. Evaluation of the antioxidant capacity of betalainic fruits and vegetables. J. Appl. Bot. Food Qual. 81:69-76.

Lim JH, Park KJ, Kim BK, Jeong JW, Kim HJ, 2012. Effect of salinity stress on phenolic compounds and carotenoids in buckwheat (Fagopyrum esculentum M.) sprout. Food Chem. 135:1065-70.

Oh MM, Rajashekar CB, 2009. Antioxidant content of edible sprouts: effects of environmental shocks. J. Sci. Food Agr. 89:2221-7.

R Development Core Team, 2013. R: A Language and Environmental for Statistical Computing. R Foundation for Statistical Computing, Vienna, Austria. Available from: http://www.R-project.org/

Re R, Pellegrini N, Proteggente A, Pannala A, Yang M, Rice-Evans C, 1999. Antioxidant activity applying an improved ABTS radical cation decolorization assay. Free Radical Bio. Med. 26:1231-7.

Shewry PR, Hey S, 2015. Do "ancient" wheat species differ from modern bread wheat in their contents of bioactive components?. J. Cereal Sci. 65:236-43.

Singleton VL, Rossi JA, 1965. Colorimetry of total phenolics with phosphomolybdic-phosphotungstic acid reagents. Am. J. Enol. Viticult. 16:144-58.

Świeca M, 2015. Production of ready-to-eat lentil sprouts with improved antioxidant capacity: optimization of elicitation conditions with hydrogen peroxide. Food Chem. 180:219-26.

Vaher M, Matso K, Levandi T, Helmja K, van Hung MK, 2010. Phenolic compounds and the antioxidant activity of the bran, flour and whole grain of different wheat varieties. Procedia Chem. 2:76-82.

Wang WB, Kim YH, Lee HS, Kim KY, Deng XP, Kwak SS, 2009. Analysis of antioxidant enzyme activity during germination of alfalfa under salt and drought stresses. Plant Physiol. Bioch. 47:570-7.

Xu JG, Tian CR, Hu QP, Luo JY, Wang XD, Tian XD, 2009. Dynamic changes in phenolic compounds and antioxidant activity in oats (Avena nuda L.) during steeping and germination. J. Agr. Food Chem. 57:10392-8.

Yang F, Basu TK, Ooraikul B, 2001. Studies on germination conditions and antioxidant contents of wheat grain. Int. J. Food Sci. Nutr. 52:319-30.

Yilmaz VA, Brandolini A, Hidalgo A, 2015. Phenolic acids and antioxidant activity of wild, feral and domesticated diploid wheats. J. Cereal Sci. 64:168-75.

Yuan G, Wang X, Guo R, Wang Q, 2010. Effect of salt stress on phenolic compounds, glucosinolates, myrosinase and antioxidant activity in radish sprouts. Food Chem. 121:1014-9.

Zhou K, Yu L, 2004. Antioxidant properties of bran extracts from Trego wheat grown at different locations. J. Agr. Food Chem. 52:1112-7. 